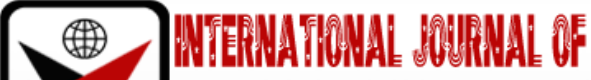 \\ בmas
}

ISSN 2278-0211 (Online)

\section{Evaluation of Southwood Education Project for Orphaned and Vulnerable Children in Lutheran Church Northern Diocese Secondary Schools in Kilimanjaro, Tanzania}

\begin{tabular}{c}
\hline Neema Gadi Masawe \\
Master's Candidate, Department of Education, Mwenge Catholic University, Tanzania \\
Joseph MMalusu \\
Professor, Department of Education, Mwenge Catholic University, Tanzania \\
Dr. Pascal Wambiya \\
Senior Lecturer, Department of Education, Mwenge Catholic University, Tanzania \\
\hline
\end{tabular}

\begin{abstract}
:
The study was formative evaluation of Southwood education project for orphaned and vulnerable children in Northern Diocese secondary schools in Kilimanjaro Region Tanzania. The study was guided by five evaluation questions in assessing the efficiency, effectiveness and utilization of resources in relation to the objectives of supporting orphaned and vulnerable children to acquire moral education. The study used mixed methods approach under convergent design in data collection, analysis and presentation. The study employed probability and nonprobability sampling technique. The target population composed Project Director. Project Administrators, Heads Schools, Teachers and students who are orphaned and vulnerable children supported by the project. Data were gathered through interview guide, and questionnaire. Quantitative data was analyzed in form of frequency, percentages and presented tables with the help of statistical Package for social sciences (SPSS) version 22. Qualitative data analysis was done through direct quotations from respondents. Major findings from the study were that: the project has succeeded the OVCs were provided with moral education training through different aspects on moral education, provision of Health care, guidance and counseling. Evaluation findings concluded that, the objectives of the project were achieved since there were provisions for training seminars for moral education content. Recommendations, in order to enhance moral content in the society the government should proceed supporting NonGovernmental Organizations on provision of education to the orphaned and vulnerable students, because when orphans and vulnerable children are not handled enough it may cause some of them to engage in drug abuse, prostitution and early marriage, the only way to help them is through providing education and protecting them especially adding number of them in boarding schools.
\end{abstract}

Keywords: Moral education, Orphaned and Vulnerable Children

\section{Introduction}

Many scholars seem to have agreed on the definition of orphan though there are some who view it slightly different from others. UNICEF (2016) and its global partners views an orphan as a child who has lost either one parent or both. Ogina, (2007), defines an orphan as a child who lost both parents and one of his or her parents. According to UNICEF's report on the 15th of June 2016, there were over 140 million orphans globally in 2015, including 52 million in Africa, 61 million in Asia, 10millionin Latin America and the Caribbean and 7.3 million in Eastern Europe and Central Asia. This large figure represents not only children who have lost both parents but also those who have lost a father but have a surviving mother or have lost mother but have a surviving father. Of these 140 million classified as orphans, 13 million have lost both parents (UNICEF, 2016). Evidence clearly shows that the vast majority of orphans are living with a surviving parent, grandparent or other family member. According to this same source, ninety-five per cent of all orphans are over the age of five.

Around the year 2000, in recognition of the complex ways that HIV and AIDS affects children and communities, development agencies began to shift away from the term AIDS Orphans to a more inclusive category, Orphans and vulnerable children or OVC (USAID, 2000); The term vulnerable was introduced as a category in its own right to describe children who were, for various reasons not limited to orphan hood, at risk of harm. The World Bank argued that a vulnerable child is one whose safety, wellbeing and development are threatened, with major dangers including lack of care, and affection, adequate shelter, education, nutrition and psychological support. (World Bank, 2004)

UNICEF (2016) proposes that majority of children who have lost a parent continue to live in the care of a surviving parent or family member. In some cases, the orphaned child has the responsibility to do house chores for siblings and dead 
parents. Carol and Boker (2011) argue that if children who have lost one to AIDS are often at risk of losing the other parent as well since HIV may have been transmitted between the couple through sex. The impact of orphan hood can be seen under emotional, physical psychological and sociological perspective. Therefore, they need moral education to overcome that emotional.

Rubaha (2008) pointed out that neglect, abuse, lack of parental love, lack of food, high labour demand at home, stigmatized at school because of lack of school uniforms and learning materials to mention but a few are some of the challenges facing orphaned students.

Kafwa (2005) argued that compared to non-orphans, orphaned students are more likely to be malnourished, more likely to drop out of school and have limited access to health social services as well as being prone to exploitation. These challenges create emotional stress making the pupils difficult to concentrate and learn in the classroom due to trauma. Hewlett (2006) argued that motivation is the drive of learning and in the case of orphans, since they lack basic needs, such as love from parents, good shelter, food and clothes then they will be less motivated to perform well in class. Maslow (2009) argued that for one to be motivated in whatever he or she does, basic needs cited above would have been satisfied. Satisfaction of these needs will enable one to perform to the expected standards.

According to Griffiths (2005) the childcare advocates work with the families to gain their grants and ensure that their rights are understood. Keeping the orphans and vulnerable children in education is also a key role of the childcare advocates. Various measures have been instituted by the national and international partners to enhance OVC accessibility to education. For example, through Free education Policy in Tanzania for primary and secondary schools introduced 2016 where OVCs has equal chance like other students to access education from primary to secondary level. Despite the fact that, measures have been taken to ensure OVCs with health services, nutrition, Shelter, and clothing as well as security and protection in Tanzania in general and other regions particularly in Kilimanjaro.

Education is a fundamental and universal basic need for all, especially orphans and vulnerable children in Tanzania. Education imparts knowledge, skills, and competencies to individuals. The findings showed that OVC had access to free primary education but had limited access to secondary education. Access to education among OVC was constrained by limited and unreliable sources of funds to meet the necessary basic needs and school requirements including food, learning materials, school uniform, and fees. (Losioki, 2020)

As the church (Lutheran church) saw the problems of these orphaned and vulnerable in Kilimanjaro region and since education is the key to development for all societies, Lutheran church decided to educate the orphanage and vulnerable children who are in danger, affected physically, emotionally and psychologically. The project has the following objectives, to offer and train orphans and vulnerable children with moral education and supports them from stage to stage to help them to fulfill their dreams through education. (Project document 2020)

\section{Purpose of Evaluation}

The purpose of this study is to evaluate the project of educating orphaned and vulnerable children in the Lutheran church in Kilimanjaro Region since 2010. This project started at Kilimanjaro due to the partnership between Southwood and Northern Diocese. Since the project started in 2010 there has been no evaluation that has been done other than monitoring reports. This study was formative evaluation because the project is still ongoing hence the purpose was to evaluate the effectiveness and efficiency of the project management, adequacy and proper use of the resources, attainment of objectives and identifying the obstacles that hinder the effective implementation of the project.

\section{Evaluation Question}

This study was guided by the following evaluation question

- How are orphaned and vulnerable children provided with moral education by the Southwood project in Northern diocese schools Kilimanjaro Region?

\section{Significance of the Evaluation}

This evaluation study provided knowledge to the management of Lutheran education project for effective implementation of the project and contribution to the advancement of knowledge to the development of the project. Lutheran education project was also benefit from this evaluation study since they may have reliable data collected by the evaluator. The findings of this study helped the Donors to satisfy themselves on how best funds and other resources have been used in the implementation of the project. The findings also benefited to the orphaned and vulnerable children who were beneficiaries of the project. Information from formative evaluation revealed the weakness of the project in order to address them. Also, the evaluation provides the room for project implementers, donors to make improvements of the project process so as to achieve the project objectives since the aim of formative is not to end up the project.

\section{Conceptual Framework}

The conceptual framework of a programme is an important tool in the monitoring and evaluation of an educational project or programme (Ogula, 2002). The conceptual framework is a mental map of understanding of how research objectives and purpose can be adequately and efficiently tackled (Omari, 2011). Conceptual framework for a programme allows programme staff to express how they use programme inputs and activities in achieving the desired effects. It also indicates the elements of a programme that needs to be monitoring and evaluation. The conceptual framework in this study is indicated at figure 1.1 


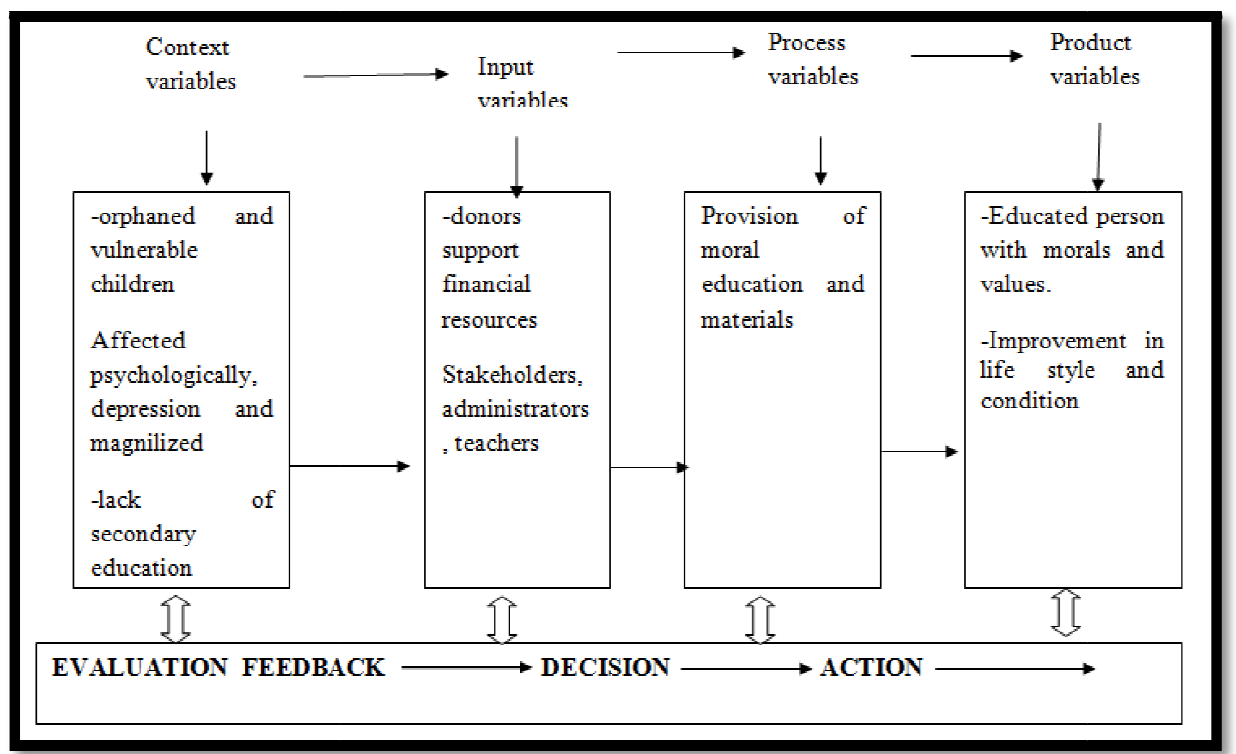

Figure 1: Conceptual Framework

Source: The Evaluator 2021

The Context included examining and describing the situation of the project in order to determine the objectives, mission and goals of the project. At this stage the evaluator evaluated the orphaned and vulnerable children background: lack of secondary education and the challenges they faced in the community.

Input: implementation of Southwood education project requires enough funds, human resources (stakeholders, administrators, and teachers), target group (orphaned and vulnerable children), teaching and learning materials.

Therefore, the evaluator evaluated whether these aspects are in place to support the implementation of the project.

Process includes how the organization is running the project. Here the evaluator evaluated all designed project activities that are facilitated by the funds and availability of different resources and facilities. Not only that but also the monitoring in order the project to run smoothly. Also, how the administrators carry out their regular supervision to ensure all the project activities are conducted well as indicated in the objectives of the project.

Product determined and examining the practice and general outcome of the project. Here the evaluator evaluated the extent to which the orphaned and vulnerable children acquired moral education to improve their life style to fit in the society. Therefore, evaluation done to give out feedback for decision making and action

\section{Review of Empirical Studies}

The scope of literature review focused on provision of moral education:

\subsection{Provision of Moral Education}

A study was conducted by Kelley, et al (2016) on ethical challenges in research with orphaned and vulnerable children in sub-Saharan Africa. Semi- structured interviews with 12 international pediatric researchers working with OVCs in seven countries were used. The study used descriptive content analysis to characterize the ethical rationale for inclusion and associated challenges. The result of the research was that, researcher believed research was justified as necessary means for informing evidence-based interventions to benefit OVCs directly or as a population. Ethical challenges included difficulty in identifying guardians among a range of caregiver's concern about meaningfulness of guardian consent, difficulty assessing risk and responding to children's many needs. This study dealt with the ethical challenges in research with orphaned and vulnerable children, the finding sought out the ethical challenges. The study left out the provision of moral education as a solution of ethical challenges the current study filled that gap.

Espoz-Lazo, et al. (2020) conducted a study motional Education for the Development of Primary and Secondary School Students through Physical Education: Emotions are embedded in the everyday life of every individual. In the same way their emotions are immersed in their cultural legacy, they are conditioned by behaviors that cannot be separated from an educational context. In this sense, physical education (PE) has been reported as a school subject that facilitates the emotional expression of primary and secondary school students. Thus, it seems to be important to understand how applied methodologies that enhance emotional education in this context help to develop students' skills regarding emotional management. In this context, 18 articles were selected from the Web of Science (WoS) under robust inclusion and exclusion criteria, which posterior were categorized and deeply analyzed. Results show that PE creates a favorable scenario for the expression of emotions. However, there is not sufficient evidence regarding emotional education methodologies that can be applied by PE teachers in their classes to improve primary and secondary students' management of emotions. It has been concluded that more proposals based on scientific evidence in this field are required. This study sought out the solution of emotions among student was the application of physical education. The finding indicated that physical education creates favorable scenario for the expression of emotions. The conclusion recommends more scientific evidence. The study left out the provision of moral education as a solution to the student emotions, 
whereby they can be taught about self-awareness, self-determination and ethical issues to reduce their emotions. The current study filled the gap by providing moral education to students.

Also, Joanna, at el. (2015) did the study aboutOrphanage caregivers' perceptions of children's emotional needs. This study explored Ghanaian institutional caregivers' views of children's emotional and relational needs with the aim of understanding these caregivers' capacities to provide effective care for orphans. Qualitative data was gathered from 92 staff at eight Ghanaian orphanages. Results indicate that while caregivers describe a basic understanding of children's emotional and interpersonal needs, they detail a lack of training and support necessary to fully attend to these needs. This study dealt with caregiver of orphaned and vulnerable children dealt with the emotional and relational needs. The results indicate that caregivers were lack of training and support necessary to fully attend to the OVCs needs. This study left out the provision of moral education to caregivers as well as the OVCs as a solution for emotional and interpersonal needs. The current study filled that gap by indicate the provision of moral education to OVCs to shape them to fit in the society.

Pillay (2020) did a study on Social Justice Implications for Educational Psychologists Working with Orphans and Vulnerable Children in South Africa. The aim of this article is to discuss the social justice implications for educational psychologists working with orphans and vulnerable children (OVC) who comprise 3.7 million of the population in South Africa. The author begins with a global conceptualization of social justice and then discusses the nature of social justice in South Africa. This is followed by an exploration of social justice within the discipline of educational psychology and how it would apply to the contexts of OVC, especially taking their psychosocial and educational challenges into consideration. These challenges allude to the point that educational psychologists have to be active agents of social justice who advocate for better learning and development opportunities for OVC to succeed in life.

Ntshute andTaukeni (2020) conducted a study on psychological and social issues Affecting Orphans and vulnerable children in addressing multicultural needs in school Guidance and counseling. The study focused on the psychological and social issues that orphans and other vulnerable children experiencing when their parents are no longer alive. Using literature as a source, most psychosocial issues affecting orphans and vulnerable children were categorized and justified. Possible solution and recommendation were clearly illustrated for possible intervention and prevention strategies. Lastly, the study ushers future research directions regarding psychological issues affecting orphans and vulnerable children. The social issues addressed were external needs such as food, shelter, clothing, education, medical care, security, love, and sense of belonging which are basic needs for human survival and developmental as well as psychological emotions, understanding and perceptions, and decision making. The study looked a lot of aspect in such a way that the evaluator could provide the results in general.

\section{Methodology}

According to Creswell (2014) evaluation design refers to the plan or proposal to conduct research involving the intersection of philosophy, strategies of inquiry and specific methods. The evaluator used the convergent design which lies on mixed paradigm. According to Creswell (2018) the mixed method research approach is the procedure for collecting, analyzing and mixing both quantitative and qualitative methods in a single study or series of the studies to understand a research problem. Data gathered through questionnaire and interview guide. Target population of the study was Project administrators, Heads of secondary schools, Teachers and students (orphans and vulnerable children) who are beneficiaries of the project. The evaluator aimed to evaluate a total of 90 students who are beneficiaries of the project, 2 Project Administrators, 9 Heads of schools, 9 schools, 27 teachers who are the guider of the orphaned and vulnerable children in schools and 1 director of the project. Although the Lutheran church has 9 schools has 2100 students and 130 teachers. The evaluator focused on 90 students who are the beneficiaries of the project and 27 teachers who are the guider of the orphaned and vulnerable children in these schools.

The probability and non-probability sampling procedures used, Samples used to provide the detailed information's includes student(s), project administrators, and heads of schools, teachers, students (orphans and vulnerable children) who are beneficiaries. Kothari (2008) explains that the good representative sample is (30\%) of the population, hence, the evaluator decided to use it to sample students since they are so many compared to other respondents who are few in numbers. Also, Kerlinger (2011) explained that an ideal sample size which is representative can range approximately from (10-30\%) of the population depending on data to be gathered and analyzed. Therefore, in this evaluation the sample size that was used ranged from (10-30\%) of population.

\section{Findings and Discussion}

The findings and discussion presented about Moral Education provided to orphaned and vulnerable children by the project:

\subsection{Moral Education Provided to Orphaned and Vulnerable Children by the Project}

The first evaluation question aimed at finding out how orphaned and vulnerable children were provided with moral education by the project. This was done through self-awareness seminars, trainings on Christian ethics and youth, ten-commandments, self-determination, Time management, the challenges faced youth and how to overcome, Health care and provision of guidance and counseling. In the self-awareness they were involves of being aware of different aspects of the self-including traits, behaviors, and feelings. Not only that but also gainingan understanding of and insight into one's strengths, qualities, weaknesses, defects, ideas, thoughts, beliefs, ideals, responses, reactions, attitude, emotions and motivations. Christianethics and Youth they were insisted of system of beliefs about moral behaviors which it is believed to be of value for personal protection, integrity and right doing. And also, an understanding of what is good or right according to their age. Ten Commandments they were insisted to adhere it as the Gods rule and guidelines of Christian Ethics. 
On the side of self-determinations which is an important concept that refers to each person's ability to make choices and manage their own life. This ability plays an important role in psychological health and well-being. They were insisted to the Determination by oneself or itself, without outside influence. Time management, they were insisted to have the ability to use one's time effectively or productively, especially at school in order to perform well in their studies, to managing time effectively so that the right time is allocated to the right activity. To making the best use of time as time is always limited and time management is the key to efficient working, increase effectiveness, efficiency, and productivity. The challenges faced youth and how to overcome, the challenges such as Isolation, Pressure for Sex, Fragmented Families, Single Parent Households Drug/Alcohol and Abuse, Violence in Schools as well as at home and peer groups. How to overcome those challenges, to share the problems, make a plan, to know that they were not alone, and ask for help. In health care they were given seminar on transmitted diseases and its impact they were training through videos. The provision of guidance and counseling, were provided to OVCs in order to help them physiologically, emotionally and encouragement in academic performance.

The evaluator collected data from teachers, students, Heads of schools, Project director and Administrators. To find out how the project provided the moral education to orphaned and vulnerable children, the questions asked to teachers and students was about attendance of seminars, and the methods used to teach in the seminars, what are the contents covered in the seminars? And if the seminars are useful to them. The responses are as follows: five (5) teachers responded by write Yes $=(62.5 \%)$ and $(3)$ said $\mathrm{No}=(37.5 \%)$ and 25 students write Yes $=(92.6 . \%)$ and $(2)$ students said $\mathrm{No}=(7.4 \%)$. Both teachers and students who said No they did not the reasons of not attending seminars. This finding implies that the project conducted seminars for orphaned and vulnerable children. The findings also indicated that the majority attending seminars training who are (5) teachers and (25) students responded to the methods used to teaching seminars are peer groups discussions, lecture, participatory and videos especially to health seminars. On peer groups discussions teachers responded are $(5)=(100 \%)$, students $(25)=(100 \%)$. Those who agreed the training through lecture methods, teachers $(5)=(100 \%)$, students $(24)=(96.3 \%)$. Participatory method they responded as follows $(5)=(100 \%)$, students $(25)=(100 \%)$. On the video method the response are $(5)=(100 \%)$, students $(25)=(100 \%)$.

Teachers and students were asked about the contents covered during the seminars. Table 1 presents teachers responses on the contents covered during the seminar.

\begin{tabular}{|c|c|c|}
\hline Statements & f & $\mathbf{\%}$ \\
\hline Self-awareness & 8 & 100 \\
\hline $\begin{array}{c}\text { Youth and Christian ethics } \\
\begin{array}{c}\text { The challenges faced youth and how to } \\
\text { overcome }\end{array}\end{array}$ & 8 & 100 \\
\hline $\begin{array}{c}\text { Importance of Adhered Ten } \\
\text { commandments }\end{array}$ & 8 & 87.5 \\
\hline Self-determinations & 7 & 87.5 \\
\hline Time management & 7 & 87.5 \\
\hline Provision of Guidance and counseling & 8 & 100 \\
\hline Transmitted diseases & 8 & 100 \\
\hline
\end{tabular}

Table 1: Response from Teachers on the Contents Covered during Seminars Source: Field Data 2021

The findings in Table 1 show that the provision of training in self-awareness to the teachers who attended the seminar was $(8)=(100 \%)$. This implies that the respondents were attaining the knowledge on self-awareness. As a result, these teachers are the guider of OVCs, therefore, they could made follow-up to the development of OVCs in their daily life in schools. Also, in the case of Youth and Christian Ethic's teacher who were training in this topic is 8= (100\%). This implies that the teachers have knowledge on Youth and Christian Ethics therefore they will insist OVCs to live morally according to what they have acquired in the training. However, on the challenges faced youth and how to overcome it, the findings indicated that, $7=(87.5 \%)$ respondents got the knowledge, which they will use to help the 0VCs in their daily life in school environment. Also, the findings indicated that on the provision of the importance of adhered Ten Commandments, self-determinations and time management, the respondent were $7=(87.5 \%)$. This implies that the majority of respondents received the knowledge provided on Ten Commandments, self-determination and time management. This will help them in their daily activities guiding OVCs to adhere Ten commandment as their Christian moral guidelines. To remind them about self-determination this could help them to have a good choice in the future without outside pressure. Also, on how to manage their time for the effectively so that the right time is allocated to the right activities in the school. Furthermore, on the concept of provision of guidance and counseling as well as health care, the findings indicated that respondents are $8=(100 \%)$. This indicates that the respondents who are teachers especially the supervising teachers of OVCs are equipped well in the guidance and counseling in order to help the OVCs in their schools. Also, to help them on the ways to avoid the transmitted diseases. The findings concur with the findings from Mwoma and Pillay (2015) who states that provision of counseling service is needed due to challenges they face on the daily basis. This indicates that the counseling services offered by the project help them to solve their daily challenges, emotional and depression. Also the findings conquer that the supervising teachers used the knowledge from the seminars to enhance moral education in schools, one of supervising teacher on the open ended question argued that 'this knowledge we get from the seminars help us much not only in guiding the OVCs but also to all students as far as our school is church 
school the student should live morally and become role model to the society as a whole' This finding was supported by one

Head of school in the interview who said that:

In our schools we enrolled these students but most of them were in the depression, stress, emotionally and others lost the directions. After attending these seminars, we observe the changes in their behavior, they started to cope with their peers, and their facial expression seems that they reduced burden. Our tasks with supervising teachers are to follow up with guidance and counseling so that they continuous to live morally.' ('interview on $03^{\text {rd }}$ June 2021)

This finding concurred to the findings which show that there were efforts in ensuring that orphans and vulnerable children get the assistance of coping with trauma after the loss of their parents. Psychosocial support helps to deal with trauma-related to their parents' death and anxiety (Lindsjo, 2018). It also helps to avoid withdrawal from social activities associated with their past experiences.

Therefore, the evaluation results affirmed that majority of respondents know how to provide moral education and guidance and counseling to students although more activities such as periodic meeting with the parents or guardian on how to provide moral education should be encouraged to facilitate community support on provision of moral education to orphan and vulnerable children. Apart from teacher's responses, Table 2 indicate the responses from students on the content covered in the seminars.

\begin{tabular}{|c|c|c|}
\hline Statements & f & $\mathbf{\%}$ \\
\hline Self-awareness & 25 & 92.6 \\
\hline Youth and Christian ethics & 27 & 100 \\
\hline The challenges faced youth and how to overcome & 26 & 96.2 \\
\hline Importance of Adhered Ten commandments & 27 & 100 \\
\hline Self-determinations & 25 & 92.6 \\
\hline Time management & 26 & 96.2 \\
\hline Provision of Guidance and counseling & 27 & 100 \\
\hline Transmitted Diseases & 27 & 100 \\
\hline
\end{tabular}

Table 2: Response from Students on the Content Covered during the Seminars Source: Field Data 2021

The findings in Table 2 show that the provision of training in self-awareness to the OVCs who attended the seminar was $25=(92.6 \%)$. This implies that the majority of respondents were training on the knowledge on selfawareness. This helped them to be aware of different aspect in their life especially on their feelings, emotions and on build the ability to hand them. Also, in the case of Youth and Christian Ethic's students who were training in this topic were 27= $(100 \%)$. This implies that the students got enough knowledge on Youth and Christian Ethics therefore they will continue to live morally according to what they have acquired in the training. However, on the challenges faced youth and how to overcome them, the findings indicated that, $26=(96.2 \%)$ respondents got the knowledge, which they will use in their daily life in school environment as well as out of school. Also, the findings indicated that on the provision of the importance of adhered Ten Commandments, the respondent were $27=(100 \%)$. This implies that the majority of respondents received the Christian guidelines so that they lived morally. Furthermore, the findings for the provision of self-determination training were $25=(92.6 \%)$. This implies that the OVCs to have a knowledge of making a good choice in the future without outside pressure. In time management findings indicated that respondents were $26=(96.2 \%)$. This implies that OVCs have knowledge on how to manage their time for the effectively so that the right time is allocated to the right activities in the school. However, the findings on provision of guidance and counseling and Health care respondents were $27=(100 \%)$. This implies that the project provided guidance and counseling to OVCs as well as training on health matters, this helped them to have good health and taking self-care.

In relation to the provision of moral education by the project, during an interview with the Project director had this to say; We give seminars to orphaned and vulnerable children to help them to reduce physiological torture from families. The seminar given was about how Christian youth to live moral life, self-awareness, self-determination, time management, Christian guidelines and Health care. This seminar was given through lecture, peer group discussion and video. We provide also guidance and counseling in the seminar and during visiting in the schools' ('interview on 07th June 2021)

These findings also supported by, one of the administrators during an interview added this:

We prepared seminars for students who are orphaned and vulnerable children twice per year, on June and December holidays. The purpose of these seminars was to encourage them to live moral life so that after completing their education studies they will be people with skills, knowledge and value whatever their serve in society. (Interview on 07th June 2021)

However, One of Head School in the interview had said that

This project gives seminars to orphaned and vulnerable twice per year, we attended to the seminar with supervising teachers in order to enhance this student to live moral life in schools, not only that but also in our school we have moral seminars to all students' ones per month in order to shape our student to live morally in schools and beyond the school.' (Interview on 04th June 2021)

The findings on how these seminars for attain moral education are useful: the evaluator in one of the evaluation seminars report it was indicated that the seminar was helpful to student behavior and they enjoyed especially when they have discussion with the peer groups about the moral issues. 
The findings concluded that the OVCs were provided with moral education through different aspects on moral education, provision of Health care and guidance and counseling. Therefore, the student to have knowledge of self-awareness, selfdetermination and time management while living in moral standards helped them to settle in schools ready to access secondary education. This finding supported by Ntshute and Taukeni (2020) conducted a study on psychological and social issues Affecting Orphans and vulnerable children in addressing multicultural needs in school Guidance and counseling. The study focused on the psychological and social issues that orphans and other vulnerable children experience when their parents are no longer alive.

\section{Conclusions and Recommendations}

\subsection{Moral Education Provided to Orphaned and Vulnerable Children by the Southwood Project in Northern Diocese Schools}

The findings from evaluation question reveal that the project has effectively implemented its objective of provision of moral education to the OVCs who are benefiting from the project, whereby the OVCs were provided with moral education training through different aspects on moral education, provision of Health care and guidance and counseling. Therefore, the student to have knowledge of self-awareness, self-determination and time management while living in moral standards helped them to settle in schools ready to access secondary education. Also, the moral education provided during the seminar training make students participated to know the challenge facing youth and how to deal with those challenges.

Also, the evaluation results affirmed that majority of teachers respondents know how to provide moral education by using different methods, and guidance to students as they were equipped well on moral education contents. Although more activities such as periodic meeting with the parents or guardian on how to provide moral education should be encouraged to facilitate community support on provision of moral education to orphan and vulnerable children.

\section{Recommendations}

In order to enhance moral content in the society the government should proceed supporting Non-Governmental Organizations on provision of education to the orphaned and vulnerable students, because when orphans and vulnerable children are not handled with care may cause some of them to engage in drug abuse, prostitution and early marriage, the only way to help them is through providing education and protecting them especially adding number of them in boarding schools.

\section{References}

i. Carol, K, and Boker T. (2011). Addressing the Educational needs of Orphans and VulnerableChildren. Policy and Research - issue 2. London: Save the Children 1 St. Johns

ii. Creswell, J.W. (2014). Research design Qualitative, Quantitative and mixed methods

iii. Approaches:

iv. Creswell, W.J. \& Creswell D.J. (2018). Research design, qualitative, quantitative and mixed methods Approaches, $5^{\text {th }}$ ed, SAGE Publication, Inc. University of Nebraska- Lincoln.

v. Espoz-Lazo, S.; Rodríguez Huete, R.; Espoz-Lazo, P.; Farías-Valenzuela, C.; Valdivia-Moral, P. Emotional Education for the Development of Primary and Secondary School Students Through Physical Education: Literature Review. Educ. Sci.2020, 10, 192.https://doi.org/10.3390/educsci10080192.

vi. Griffiths, J. (2005). HIV/AIDS Intervention Programs for Youth in Africa: The Role of Grassroots Soccer, Stanford University.

vii. Hewlett, L. (2006). Youth Sexuality and HIV/AIDS Prevention: A Literature Review, Graduate School of Public and Development Management: University of Witwatersra(Master's Thesis)

viii. Joanna, E.B, Jamie, M.M. \&Kofi, O.K (2015).Orphanage caregivers' perceptions of children's emotional needs Children and Youth Services ReviewVolume 49, February 2015,Pages

ix. Kafwa, V. N. (2005) Effectiveness of AIDS Education Programs in Secondary Schools in Busia District Unpublished M Phil Thesis: Moi University

x. Kelley, M.C., Brazg, T., Wilford, B.S., Lengua L.J., Rivin, B.E., \&Diekema, D.S. (2016). Ethical challenges in research with orphaned and vulnerable children, a qualitativestudy of research experiences. International Health, 8(3), 187-196.

xi. Kerlinger, F.N. (2011). Foundation of educational Research. Washington America educational Research Association Kilimanjaro Centre registered charity (2018) 07NG0/1812

xii. Kothari, C.R. (2008). Research Methodology: Methods and techniques, 2th Ed. New Delhi: New Age International Publisher.

xiii. Lindsjö, K. (2018). The financial burden of a fee free primary education on rural livelihoods-a case study from rural Iringa Region, Tanzania. Development Studies Research, 5(1), 26-36

xiv. Losioki, B. (2020). Education Opportunities and Support for Orphans and Vulnerable Children in Bagamoyo District Tanzania. MwalimuNyerere Memorial Academy

xv. Maslow, J. (2009) Maslow Pyramid gets a much-needed renovation: ASU

xvi. Mwoma, T; Pillay, J. (2016). Educational Support for Orphans and Vulnerable Children in Primary Schools: Challenges and Interventions Issues in Educational Research, South AfricanJournalv26 n1 p82-97 2016

xvii. Ntshute, Z. \&Taukeni, S.G. (2020). Psychological and social issues affecting orphans andvulnerable children in addressing Multicultural Needs in School Guidance and counseling (pp.20-30) IGI Global. 
xviii. Ogina, A.T. (2007). Redefining the role educators in managing the need of Orphaned Learners. University of Pretoria.

xix. Ogula, P.A, (2002). Monitoring and Evaluation of Educational Projects and Programmes. Nairobi. New Kemit Publishers

xx. Omari, I.M., (2011), Concepts and Methods in Educational Research. Dar es Salaam Oxford University Press.

xxi. Pillay, J. Social Justice Implications for Educational Psychologists Working with Orphans and Vulnerable Children in South Africa School; Psychology International, v41 n1 p37-52 Feb 2020

xxii. Rubaha, R.F. (2008). Factors influencing good performance in Tanzania school: University of Dar es Salaam.

xxiii. UNICEF/ Orphans (2016). Monitoring the situation of children and women. Retrieved from: http//www.data unicef .org on 15/12/2018

xxiv. USAID. (2000). Children on the Brick 2000. Washington, DC.

xxv. World Bank. (2004). Reaching out to Africa's orphans: A framework for Public Action Africa Region (Human development) and Human Development Network (social Protection) 